\title{
NOTES ON INTERSPECIFIC, MIXED COLONIES IN THE HARVESTER ANT GENUS POGONOMYRMEX
}

\author{
By Bert Hölldobler* and Hubert MarkL**
}

During our long-term investigations on colony interactions and communication in the harvester ants (Pogonoymrmex) in the Chihahuan desert near Portal, Arizona and Rodeo, New Mexico, we occasionally observed interspecific, mixed colonies of $P$. rugosus and $P$. barbatus. In all cases it appeared that $P$. barbatus workers were incorporated into a $P$. rugosus nest, because $P$. barbatus were by far in the minority.

We first noted this phenomenon in July 1974, when we encountered a $P$. rugosus nest, where approximately $5 \%$ of the workers emerging from the nest entrance were $P$. barbatus. Between 1974 and 1988 we observed 9 additional such incidents. The percentage of $P$. barbatus workers recorded at the nest entrance of $P$. rugosus nests varied from $3 \%$ to $11 \%$. In most cases the P. barbatus workers were engaged in foraging, and no difference in behavior was noticed between the $P$. barbatus foragers and their $P$. rugosus nestmates. There was, however, one remarkable exception. In July 1988 we observed a large $P$. rugosus colony where workers of this species were carrying $P$. barbatus workers out of the nest and were releasing them a few centimeters to approximately $2 \mathrm{~m}$ from the nest entrance. During transportation the $P$. barbatus workers assumed a pupal posture, with the appendages tightly folded to the body. When released they often remained in this position for a few seconds until they "unfolded" and returned to the nest. From a total of $20 P$. barbatus workers marked with fast drying enamel, we verified that individual $P$. barbatus workers may be carried out repeatedly. In one case we recorded a worker being evicted from the nest 19 times within 3 hours. We observed this behavior for 12 days, when it finally began to wane and within the following two days it ceased

\footnotetext{
*Department of Organismic and Evolutionary Biology, Harvard University, Cambridge, Mass. 02138, USA. Current address: Zoologisches Institut der Universität Würzburg, 8700 Würzburg, Federal Republic of Germany.

**Fachbereich Biologie, Universität Konstanz, Konstanz, Federal Republic of Germany.

Manuscript received by the editor June 15, 1989.
} 
completely. From the appearance of the cuticle and the development of their ovaries and fat bodies we concluded that these $P$. barbatus workers were young ants. During the following 3 weeks we noticed only occasionally a few $P$. barbatus workers patrolling the vicinity of the nest entrance, but we did not see them foraging.

How do these interspecific mixed colonies originate? During our investigations of intra- and interspecific interactions in Pogonomyrmex populations, we repeatedly observed mature $P$. rugosus colonies raid smaller colonies of other congeneric species. We recorded such raids on conspecific nests (3 times), on nests of $P$. barbatus (4 times), on $P$. desertorum (once) and on $P$. maricopa (once). We also twice observed raids conducted by $P$. barbatus on small $P$. rugosus colonies that were approximately 1-2 years old. In several of these cases we noted that the raiders completely wiped out the raided colonies, pillaging live and dead workers, and brood. In one case we observed a mature $P$. rugosus colony raiding a $P$. barbatus nest $12 \mathrm{~m}$ away and capturing at least 46 pupae and 22 larvae. We checked this site two years later and did not find any sign of the raided colony, whereas the $P$. rugosus colony was still at the same location.

These observations suggest that interspecific mixed colonies in Pogonomyrmex might result from territorial raids. Although laboratory experiments indicate that a large portion of the captured brood of other Pogonomyrmex species is eaten by the raiders, $P$. rugosus readily adopts brood of $P$. barbatus (and vice versa), so that the foreign pupae may eclose in the raiders' nest and can subsequently serve as slave workers.

Acknowledgment: We thank Stefan Cover for verifying the identification of the ants and for his comments. 

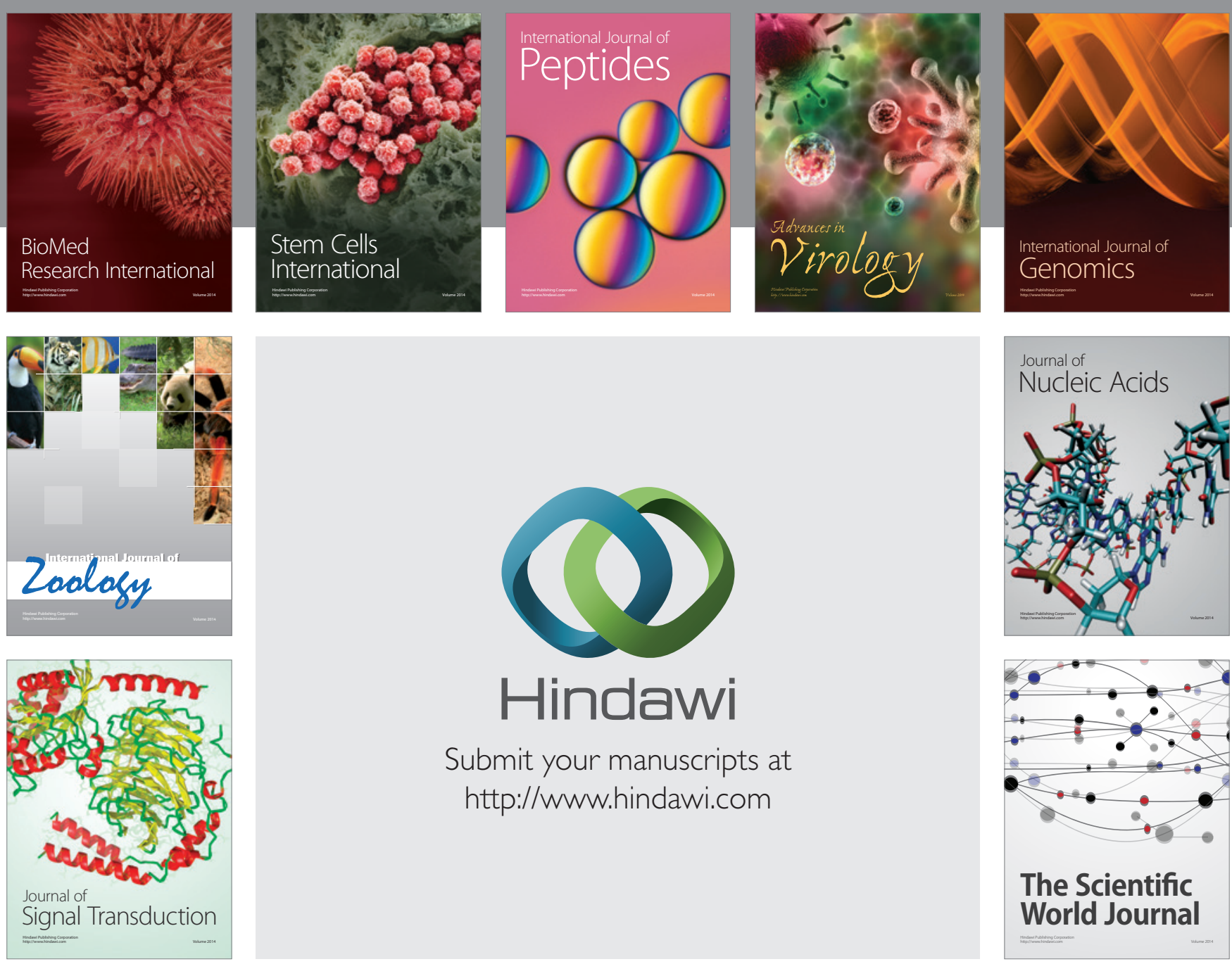

Submit your manuscripts at

http://www.hindawi.com
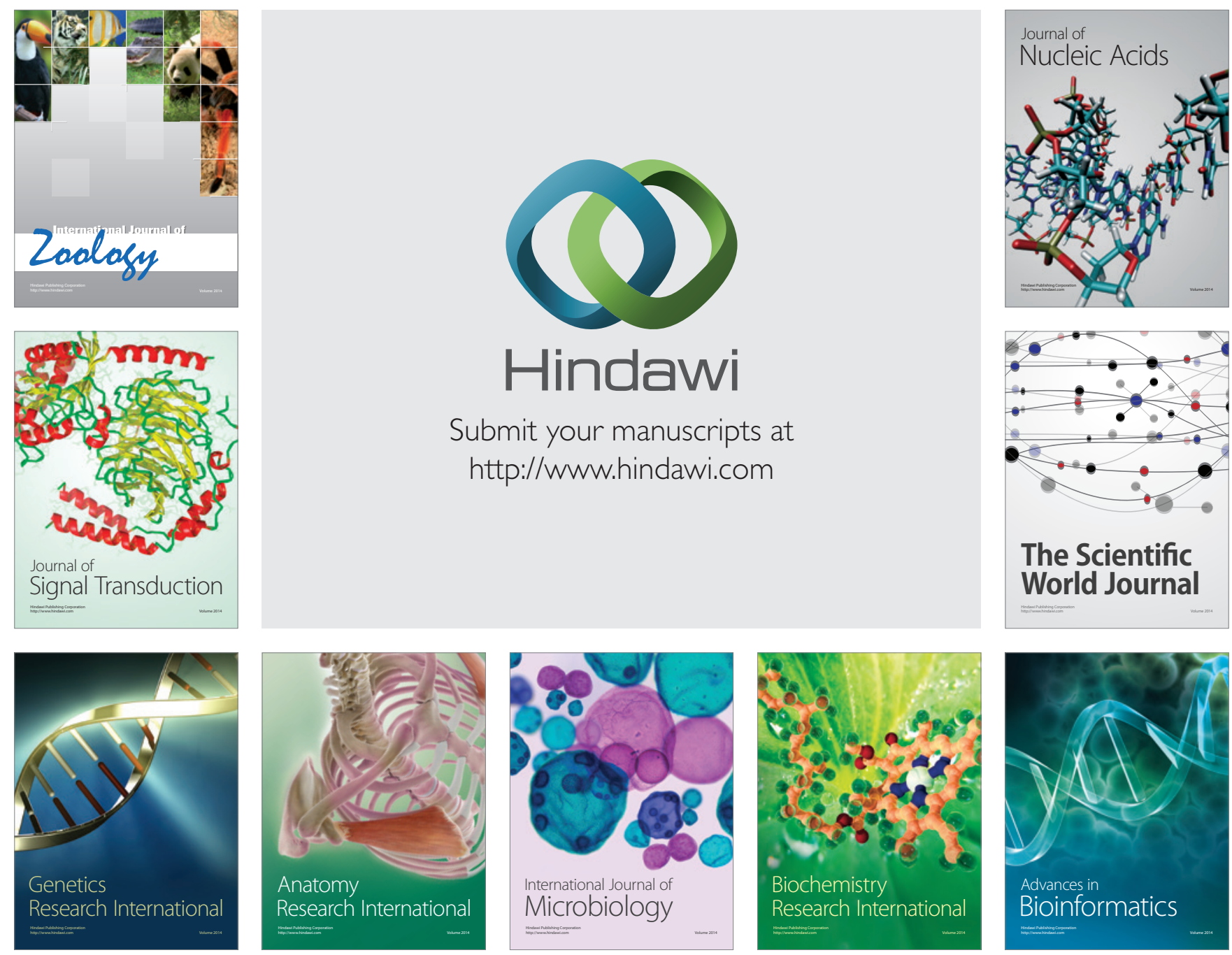

The Scientific World Journal
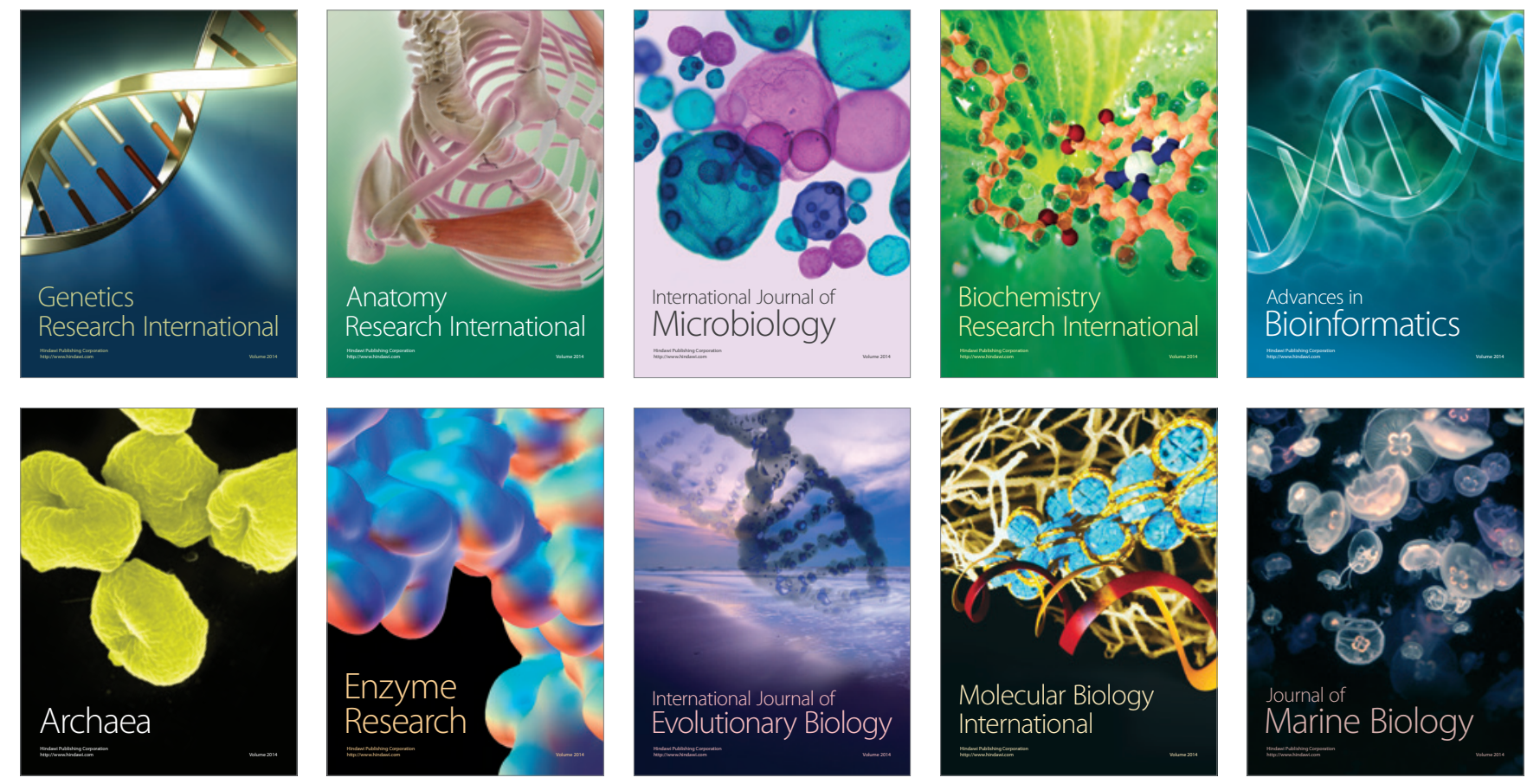